\title{
Cardiac MRI Improves Identification of Etiology of Acute Ischemic Stroke
}

\author{
Alex Baher $^{\mathrm{a}, \mathrm{b}} \quad$ Ashkan Mowlac, e Santhisri Kodali $^{\mathrm{b}} \quad$ Venkateshwar R. Polsani $^{\mathrm{d}}$ \\ Faisal Nabi $^{d}$ Sherif F. Nagueh ${ }^{d}$ John J. Volpic Dipan J. Shah ${ }^{d}$

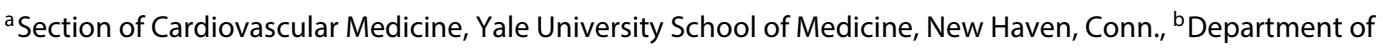 \\ Medicine, The Methodist Hospital, ' Department of Neurology, Methodist Neurological Institute, dHouston \\ Methodist Heart \& Vascular Center, Houston, Tex., and eDepartment of Neurology, State University of New York at \\ Buffalo, Buffalo, N.Y., USA
}

\section{Key Words}

Ischemic stroke · Stroke subtype · Cardiac magnetic resonance $\cdot$ Cryptogenic stroke $\cdot$ Cardioembolic stroke

\begin{abstract}
Background: An accurate subtype classification of acute ischemic stroke is important in clinical practice as it can greatly influence patient care in terms of acute management and devising secondary stroke prevention strategies. Approximately, one third of ischemic strokes are cryptogenic despite a comprehensive workup. Diagnostic workup for detecting cardioaortic sources of cerebral embolism commonly includes transthoracic echocardiography (TTE). However, TTE has a limited diagnostic power to detect some of the cardioaortic abnormalities and additional imaging modalities are often needed to accurately assess such abnormalities. Purpose: We evaluated the feasibility of cardiovascular magnetic resonance (CMR) imaging to detect the cardioaortic sources of ischemic stroke. Methods: A total of 106 patients were included, of which 85 had an ischemic stroke and 21 had a transient ischemic attack (TIA). Routine diagnostic workup (RDW) included brain diffusion-weighted image MRI, telemetry, magnetic resonance angiography/CT angiography of head and neck, carotid duplex ultrasonography, laboratory studies and TTE. Patients additionally underwent CMR. Subtype assignment was performed in accordance with the Stop Stroke Study of the Trial of Org
\end{abstract}

\begin{tabular}{ll}
\hline KARGER & $\begin{array}{l}\text { ( 2014 S. Karger AG, Basel } \\
\text { 1015-9770/14/0374-0277\$39.50/0 Open ciccess }\end{array}$ \\
$\begin{array}{l}\text { E-Mail karger@karger.com } \\
\text { www.karger.com/ced }\end{array}$ & $\begin{array}{l}\text { This is an Open Access article licensed under the terms of the } \\
\text { Creative Commons Attribution-NonCommercial 3.0 Un- } \\
\text { ported license (CC BY-NC) (www.karger.com/OA-license), } \\
\text { applicable to the online version of the article only. Distribu- } \\
\text { tion permitted for non-commercial purposes only. }\end{array}$
\end{tabular}

10172 in Acute Stroke Treatment classification system by a stroke neurologist after reviewing the admission notes and diagnostic test results. A second subtype classification was assigned with an additional criterion defined based on delayed enhancement (DE)-CMR findings. Additionally, the presence of non-coronary artery disease (CAD) scarring was assessed in ischemic stroke patients and compared with the TIA patients as the control group. Results: RDW detected cardioaortic embolism (CAE) stroke in 32 (37.6\%) patients and cryptogenic stroke in 23 patients (27.1\%). Addition of CMR resulted in a $26.1 \%$ reduction in the rate of cryptogenic strokes (6 patients). Furthermore, DE-CMR findings allowed for reclassification of three additional cryptogenic subtypes, resulting in a $39.1 \%$ reduction of cryptogenic stroke rate. Non-CAD scarring was detected in $13(15.3 \%)$ stroke patients as opposed to only $1(4.8 \%)$ TIA patient. Conclusions: CMR is a valuable tool for the detection of CAE sources in patients with cryptogenic ischemic stroke and provides clinicians with a unique set of information that may substantially change the long-term management of these patients. DE-CMR also detects non-CAD scarring, which may indicate a predisposition to ischemic stroke. Further studies with larger samples and long-term follow-up are needed to further evaluate the clinical significance of our findings.

(c) 2014 S. Karger AG, Basel

A.B. and A.M. contributed equally to this work.
Dipan J. Shah, MD, FACC

Associate Professor of Clinical Medicine, Weill Cornell Medical College

Director of Cardiovascular MRI Laboratory, Houston Methodist Heart \& Vascular Center 6550 Fannin, Suite 677, Houston, TX 77030 (USA)

E-Mail djshah@houstonmethodist.org 


\section{Introduction}

Accurate subtype classification of ischemic strokes is invaluable as outcome, recurrence rate, and secondary prevention strategies differ by the subtype [1-3]. The most widely accepted classification system of stroke subtype is the Trial of Org 10172 in Acute Stroke Treatment (TOAST) developed in 1993 [4]. This classification system was updated in Stop Stroke Study TOAST (SSSTOAST) $[5,6]$. SSS-TOAST was designed to improve interexaminer reliability when multiple competing underlying sources are identified.

Diagnostic workup for detecting cardioaortic sources of cerebral embolism commonly includes transthoracic echocardiography (TTE) $[7,8]$. TTE is a noninvasive, portable, and widely available tool, with the power to detect most cardioaortic embolism (CAE) strokes [7, 9]. However, TTE has a limited diagnostic power for the detection of some abnormalities such as left atrial (LA) appendage thrombus, or ascending aortic lesions [10]. In such cases, additional diagnostic cardiac imaging techniques may be required. Despite recent advances in imaging, a CAE source cannot be identified in a number of patients in whom other subtypes are ruled out. These 'cryptogenic' strokes pose a challenge to clinicians in terms of acute and long-term management. The incidence of cryptogenic stroke is $25-39 \%$ in different registries $[2,11,12]$.

Cardiovascular magnetic resonance (CMR) is a novel imaging modality increasingly used for evaluation of various cardiovascular pathologies. Its role in the assessment of CAE strokes has been suggested previously [13, 14], however, except for three small limited studies, which looked at specific pathologies [15-17], CMR's utility to detect all sources of cerebral embolism is not well established. We evaluated the feasibility of using CMR to assess cardiac and aortic sources of acute cerebral embolism.

\section{Methods}

\section{Study Population}

This was a single-center prospective study at the Methodist Hospital (Houston, Tex., USA). A total of 141 consecutive patients admitted to one of the stroke services with stroke-like symptoms were approached. Stroke severity was initially estimated using the National Institute of Health Stroke Scale. Thirty-five patients did not complete the study due to either patient refusal, technical difficulties, or scheduling conflicts. The remaining patients were enrolled and a written informed consent was obtained. The study was approved by our local Institutional Review Board. The inclusion criteria were presence of stroke symptoms along with positive findings on diffusion-weighted imaging (DWI)-MRI of the brain. Patients with a transient ischemic attack (TIA), defined as transient neurological dysfunction caused by focal brain ischemia but a negative DWI-MRI, were used as controls [18]. The exclusion criteria consisted of evidence of intracranial hemorrhage on the initial head CT and presence of metallic prosthetics or implanted devices.

\section{Routine Diagnostics}

Patients received the following routine diagnostic workup (RDW): laboratory studies, DWI-MRI, magnetic resonance angiography or CT angiography of head and neck, carotid Doppler ultrasonography, electrocardiogram, telemetry monitoring, and TTE. Laboratory studies included cardiac enzymes, basic metabolic panel, urine analysis, complete blood count, and lipid panel. Patients with a predisposition to thrombophilia additionally underwent hypercoagulability workup. The degree of internal carotid artery stenosis was estimated using the North American Symptomatic Carotid Endarterectomy Trial protocol [19]. Eligibility to receive acute thrombolytic therapy was determined on an individual basis according to established guidelines.

\section{Cardiac Imaging}

Echocardiogram Image Acquisition and Interpretation

Standard two-dimensional color Doppler and spectral Doppler ultrasound imaging were performed. The equipment was from multiple vendors which were used based on availability. Parasternal short- and long-axis, as well as apical two-, three-, and fourchamber imaging planes were acquired. Saline contrast was used during all studies, at rest and during Valsalva. Echo-contrast (Definity, Lantheus Medical Imaging, Mass., USA) was reserved for selective cases based on current recommendations [20]. All studies were interpreted by level-III trained echocardiographers.

CMR Protocol, Image Acquisition, and Image Interpretation Images were acquired using 1.5-tesla scanners (Siemens Sonata or Avanto, Siemens, Malvern, Pa., USA) equipped with a 16-channel cardiac coil. Cine-CMR images were generated using a steady-state free-procession sequence (SSFP) as previously described [21]. Serial high-resolution SSFP short-axis views of the atria ( $4 \mathrm{~mm}$ thickness and 0 gap) were used to assess the presence of interatrial septal aneurysms (IASAs). Evaluation for patent foramen ovale (PFO) and atrial septal defects was done using SSFP cine-CMR and velocity-encoded phase contrast imaging (slice thickness $6 \mathrm{~mm}$, in-plane resolution $2.0 \times 1.5 \mathrm{~mm}$, echo time $1 \mathrm{~ms}$, temporal resolution $42 \mathrm{~ms}$, flip angle $30^{\circ}$, and velocity encoding $80-120 \mathrm{~cm} / \mathrm{s}$ ).

Assessment of intracardiac and aortic mural thrombi was done using inversion recovery SSFP acquisition with a long inversion time to directly image thrombi [22]. Contrast-enhanced three-dimensional angiography of the thoracic aorta was also performed to detect other aortic pathologies [23]. Delayed enhancement (DE)-CMR images were obtained using a previously established protocol [24]. Patients with glomerular filtration rate $\geq 30 \mathrm{ml} /$ $\mathrm{min} / 1.73 \mathrm{~m}^{2}$ received a gadolinium-based contrast (Magnevist, Bayer Schering Pharma, Berlin, Germany); an iron-based contrast was used in those with glomerularfiltration rate $<30 \mathrm{ml} / \mathrm{min} / 1.73 \mathrm{~m}^{2}$. The DE-CMR images were analyzed for the presence, extent, and location of scar. Abnormalities that were subendocardial in origin or transmural and consistent with a coronary artery perfusion ter- 
ritory were deemed to represent myocardial infarction. Abnormalities that were epicardial, mid-myocardial, or not consistent with a coronary artery perfusion territory were deemed to represent non-coronary artery disease (CAD) scarring. All studies were interpreted by level-III cardiac MRI-trained cardiologists who were unaware of the routine workup findings.

Stroke Subtype Classification

Determination of Stroke Subtype

Ischemic stroke subtype assignment was performed according to the SSS-TOAST classification system. The following subtypes were considered: (1) large artery atherosclerosis (LAA), (2) CAE, (3) small artery disease, (4) other determined causes (ODC), and (5) cryptogenic. When multiple sources existed, a computerized algorithm developed by SSS-TOAST was used to determine the most likely subtype [6]. In each case, 2 experienced stroke neurologists determined the appropriate subtype after reviewing all available data.

\section{Identification of CAE Sources}

A CAE source was defined as the presence of either an evident or a possible source within the cardiac chambers as well as the thoracic aorta and aortic arch. A primary and a secondary CAE subtype classification was performed. In the primary CAE subtype assignment, evident and possible sources were assessed as defined in SSS-TOAST. Evident sources included LA, left ventricle (LV) or aortic thrombus, atrial fibrillation, sick sinus syndrome, sustained atrial flutter, recent myocardial infarction, rheumatic valve disease, bioprosthetic or mechanical valves, chronic myocardial infarction with ejection fraction $<28 \%$, congestive heart failure with ejection fraction $<30 \%$, dilated cardiomyopathy, endocarditis, papillary fibroelastoma, and LA mass. The possible sources included mitral annular calcification, PFO, IASA, PFO with IASA, LV aneurysm without thrombus, isolated LA smoke, and complex atheroma in the ascending aorta or proximal arch [5].

In the secondary CAE subtype assignment, the findings of DECMR were used to establish a new criterion for identification of CAE stroke, additional to ones defined in SSS-TOAST. Specifically, the concurrence of transmural myocardial scarring on DECMR and akinesis/hypokinesis on CMR in multiple wall segments $(\geq 3)$ was considered a significant source of cardioembolism. The justification for this new criterion was based on recent data, which recognized transmural scarring detected by DE-CMR as a novel and independent predictor of LV thrombosis. According to this data, our $\geq 3$ segment cutoff would correspond to a $\geq 10 \%$ risk of presence of LV thrombus [22].

\section{Statistical Analysis}

All data are listed as raw values and in percentages. We used McNemar's test to calculate the significance of the change in the cryptogenic stroke group.

\section{Results}

In total, 106 patients (50 males), with an average age of $64.7 \pm 15.7$ (mean \pm SD) years, were enrolled. Eighty-five patients $(80.2 \%)$ had a DWI-MRI-confirmed acute isch-
Table 1. Baseline characteristics of patients presenting with signs and symptoms of an acute stroke

\begin{tabular}{lccc}
\hline & $\begin{array}{l}\text { Total } \\
(\mathrm{n}=106)\end{array}$ & $\begin{array}{l}\text { Stroke } \\
(\mathrm{n}=85)\end{array}$ & $\begin{array}{l}\text { TIA } \\
(\mathrm{n}=21)\end{array}$ \\
\hline Sex, male & $50(47.2)$ & $40(47.1)$ & $10(47.2)$ \\
Age (mean \pm SD) & $64.7 \pm 15.7$ & $66.3 \pm 14.8$ & $57.0 \pm 17.0$ \\
Race & & & \\
$\quad$ White & $47(44.3)$ & $38(44.7)$ & $9(42.9)$ \\
$\quad$ Black & $29(27.4)$ & $24(28.3)$ & $5(23.8)$ \\
$\quad$ Hispanic & $18(17.0)$ & $15(17.6)$ & $3(14.3)$ \\
$\quad$ Other & $12(11.3)$ & $8(9.4)$ & $4(19.0)$ \\
Atrial fibrillation & $16(15.1)$ & $14(16.5)$ & $2(9.5)$ \\
Diabetes mellitus & $30(28.3)$ & $24(28.2)$ & $6(28.6)$ \\
Hypertension & $80(75.5)$ & $68(80.0)$ & $12(57.1)$ \\
Hyperlipidemia & $49(46.2)$ & $39(45.9)$ & $10(47.6)$ \\
Family history of CAD/CVA & $23(21.7)$ & $18(21.2)$ & $5(23.8)$ \\
CAD & $24(22.6)$ & $22(25.9)$ & $2(9.5)$ \\
Previous TIA/CVA & $23(21.7)$ & $20(23.5)$ & $3(14.3)$ \\
Smoking & $19(17.9)$ & $14(16.5)$ & $5(23.8)$ \\
Alcohol use & $20(18.9)$ & $16(18.8)$ & $4(19.0)$ \\
Medications & & & \\
$\quad$ ASA & $38(35.8)$ & $30(35.3)$ & $8(38.1)$ \\
Clopidogrel & $17(16.0)$ & $13(15.3)$ & $4(19.0)$ \\
Anticoagulant & $8(7.5)$ & $8(9.4)$ & $0(0.0)$ \\
Beta-blocker & $49(46.2)$ & $42(49.4)$ & $7(33.3)$ \\
ACEI/ARB & $41(38.7)$ & $34(40.0)$ & $7(33.3)$ \\
Calcium channel blocker & $28(26.4)$ & $21(24.7)$ & $7(33.3)$ \\
Statin & $27(25.5)$ & $26(30.6)$ & $1(4.8)$ \\
\hline
\end{tabular}

Number of patients with percentages in parentheses. CVA = Cerebrovascular accident; ACEI = angiotensin-converting enzyme inhibitor; $\mathrm{ARB}=$ angiotensin II receptor blocker.

emic stroke, and 21 (19.8\%) had a TIA. The baseline characteristics of the stroke and TIA populations are presented in table 1 .

A primary ischemic stroke subtype classification, as described in SSS-TOAST, was performed in two ways: (1) using only the RDW data and (2) using the CMR data in addition to the RDW findings (table 2). With RWD data alone, 20 (23.5\%) of the strokes were classified as LAA, 32 $(37.6 \%)$ as CAE, $2(3.5 \%)$ as small artery disease, and 7 $(8.2 \%)$ as ODC. The remaining $23(27.1 \%)$ strokes were classified as cryptogenic. The relevant CMR/DE-CMR findings in the cohort are summarized in table 2.

Within the LAA stroke group, 10 patients had middle cerebral artery stenosis, 6 patients had internal carotid artery stenosis, and 4 patients had vertebral artery stenosis.

RDW detected 27 (81.3\%) evident and 5 (18.7\%) possible embolic sources among the CAE stroke patients. 
Fig. 1. Cardiovascular sources of embolism detected by CMR in patients with cryptogenic stroke. a Apical thrombus (arrow) using the thrombus imaging technique (TI-600) in two-chamber view. b Axial image of the thoracic aorta representing a thrombus in the ascending aorta (arrow). c An SSFP still frame of the oblique sagittal view showing a patent foramen ovale. $\mathrm{TI}=$ Time to inversion; $\mathrm{LV}=$ left ventricle; $\mathrm{LA}=$ left atrium; $\mathrm{AO}=$ aorta; $\mathrm{RA}=$ right atrium; $\mathrm{PA}=$ pulmonary artery.
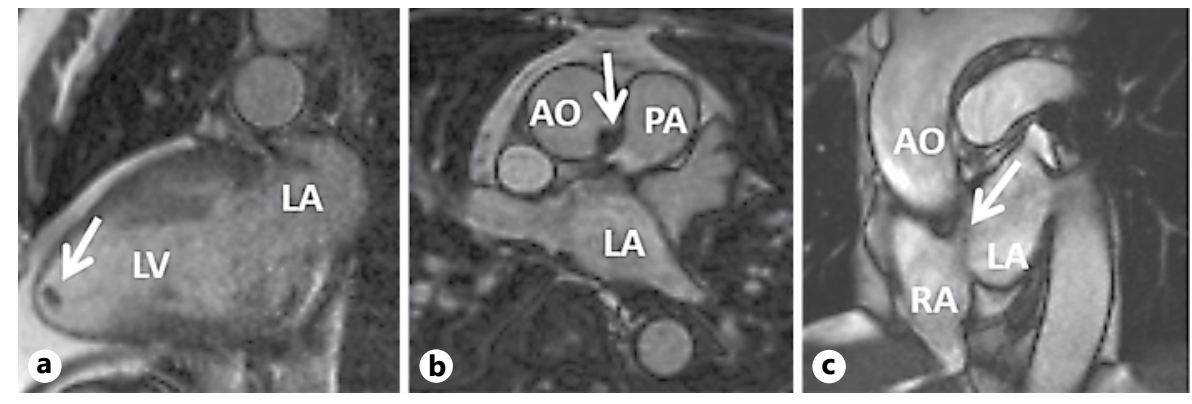

Table 2. CMR/DE-CMR findings in the study population

\begin{tabular}{llllllllll}
\hline \multicolumn{2}{l}{ CMR/DE-CMR findings, $\mathrm{n}$} \\
\hline type
\end{tabular}

Thrombus = LA, LV, or ascending aortic thrombus; mass = LA mass/myxoma/abscess; $\mathrm{MAC}=$ mitral annular calcification; $\mathrm{SAD}=$ small artery disease.

${ }^{\text {a }}$ Classification of stroke patients is based on RDW.

Table 3. Stroke subtype classification based on SSS-TOAST criteria $(\mathrm{n}=85)$

\begin{tabular}{lccl}
\hline Type of stroke & RDW $^{\mathrm{b}}$ & RDW +CMR & \% change \\
\hline LAA & $20(23.5)$ & $20(23.5)$ & 0.0 \\
CAE $^{\mathrm{a}}$ & $32(37.6)$ & $38(44.7)$ & 18.8 \\
Small artery disease & $3(3.5)$ & $3(3.5)$ & 0.0 \\
ODC & $7(8.2)$ & $7(8.2)$ & 0.0 \\
Cryptogenic & $23(27.1)$ & $17(20.0)$ & $-26.1^{*}$ \\
\hline
\end{tabular}
0.01 .

Number of patients with percentages in parentheses. ${ }^{*} \mathrm{p}=$

a Data includes both evident and possible sources.

The evident embolic sources included atrial fibrillation (18 patients), LV thrombus (2 patients), congestive heart failure with ejection fraction $<30 \%$ ( 4 patients), LA mass (1 patient), and bioprosthetic valve (1 patient). The possible embolic sources included mitral annular calcification (2 patients), PFO (2 patients), IASA ( 1 patient) and PFO with IASA (1 patient). In patients with ODC stroke,
1 had a vertebral artery dissection, 1 had an internal carotid artery dissection, 2 had hypercoagulable states, and 3 had hypotensive watershed infarctions.

The use of CMR data in combination with RDW detected six additional sources of CAE, thereby reducing the rate of cryptogenic stroke by $26.1 \%$ (table 3 ). Of these patients, 3 had an evident embolic source and were started on anticoagulation therapy. The evident sources included LV thrombus in 2 patients and a complex ascending aortic thrombus in 1 patient (fig. 1). In the remaining 3 patients, CMR detected a possible embolic source, which included IASA (2 patients) and IASA with PFO (1 patient).

A secondary CAE subtype classification was performed with inclusion of the additional criterion described earlier for CAE identification. In 3 patients with cryptogenic stroke, DE-CMR detected multiple segments $(\geq 3)$ of transmural scarring in addition to the multiple $(\geq 3)$ akinetic or hypokinetic wall segments detected by cine-CMR (fig. 2). The rates of CAE and cryptogenic strokes with RDW and with RDW plus cine- and DECMR are shown in table 4. Use of DE-CMR in addition 
Fig. 2. Concurrent presence of transmural scarring plus wall segment akinesis. a, b Systolic and diastolic SSFP images of the mid short axis of the left ventricle (LV) showing a thinned akinetic lateral wall (arrows). c Delayed hyperenhancement image showing a transmural scar in the lateral segment (arrow). RV = Right ventricle.
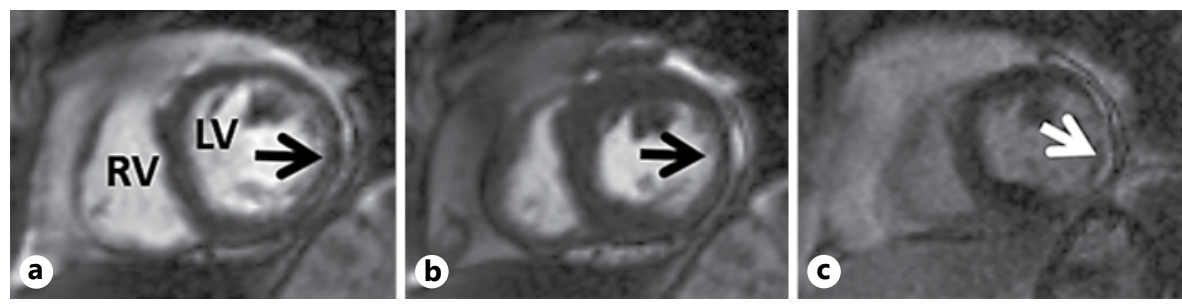
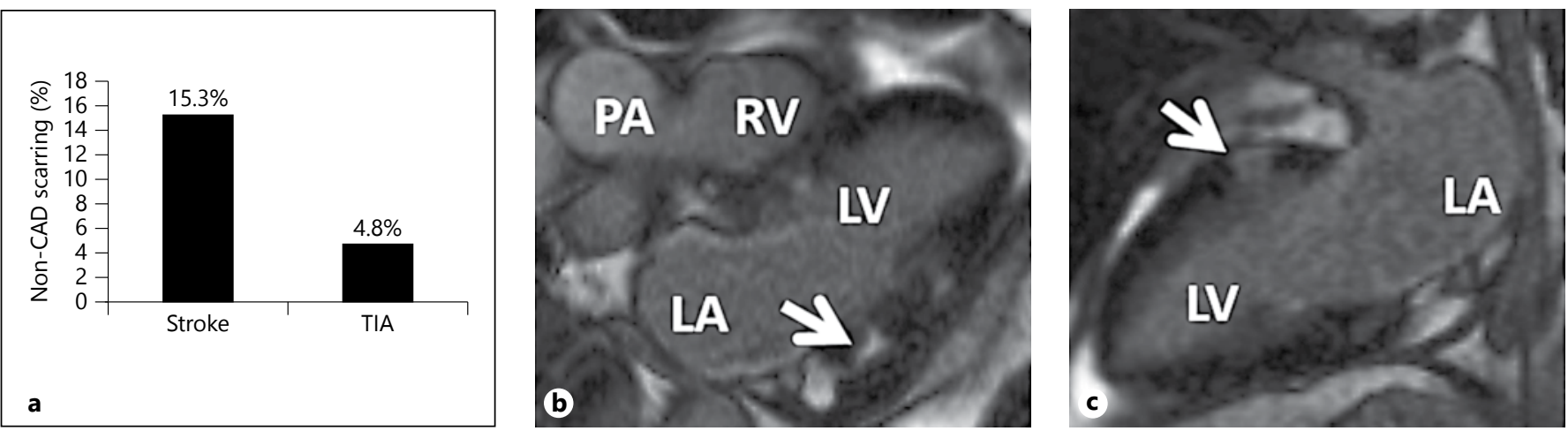

Fig. 3. Non-CAD scarring pattern on DE-CMR. a Comparison between incidences of non-CAD scarring in stroke vs. TIA patients. b, c Delayed hyperenhancement images of three chambers and two chambers of the left ventricle (LV) showing the non-CAD distribution of scarring in the inferolateral (b) and basal anterior (c) walls (arrows). PA = Pulmonary artery; LA = left atrium; RV = right ventricle. to cine-CMR reduced the cryptogenic stroke rate by a total of $39.1 \%$.

The incidence of non-CAD scarring was also assessed in the stroke and TIA groups (fig. 3). Non-CAD scarring referred to myocardial scarring detected by DE-CMR with features not consistent with ischemic heart disease was present in 13 (15.3\%) patients with an acute stroke. Only $1(4.8 \%)$ patient with a TIA had evidence of nonCAD scarring on DE-CMR.

\section{Discussion}

The present study evaluated the utility of CMR for detecting CAE strokes. The major findings are as follows: (1) CMR effectively detected either an evident or a possible embolic source in $26.1 \%$ of patients with cryptogenic strokes. (2) Inclusion of an extra criterion in reference to DE-CMR findings resulted in a $39.1 \%$ reduction in cryptogenic stroke rate. (3) A higher incidence of nonCAD scarring was observed in patients with ischemic stroke compared to patients with TIA.

Cardiac MRI Improves Identification of

Etiology of Acute Ischemic Stroke
Table 4. Stroke subtype classification with the modified SSSTOAST criteria $(\mathrm{n}=85)$

\begin{tabular}{lllc}
\hline Type of stroke & RDW & $\begin{array}{l}\text { RDW +CMR/ } \\
\text { DE-CMR }\end{array}$ & \% change \\
\hline CAE $^{\mathrm{a}}$ & $32(37.6)$ & $41(48.2)$ & 28.1 \\
Cryptogenic & $23(27.1)$ & $14(16.5)$ & $-39.1^{*}$ \\
\hline
\end{tabular}

Number of patients with percentages in parentheses. ${ }^{*} \mathrm{p}=$ 0.003 .

${ }^{\text {a }}$ Data includes both evident and possible sources.

The detection of CAE sources has important prognostic implications in the management of acute ischemic stroke $[25,26]$. Compared with other subtypes, CAE stroke has the poorest long-term outcomes [27]. Currently, there is no consensus on an optimal imaging modality to diagnose CAE stroke [28]. Such an imaging technique should survey LV, LA, as well as the thoracic aorta and aortic arch to detect high-risk sources requiring anticoagulation therapy [25]. Ideally, such a tech- 
nique would also detect other, controversial but possible, embolic sources such as PFO and IASAs. Further study of these controversial sources is necessary to support a causal link that may translate to more efficacious management.

\section{Use of CMR to Detect Cardiac and Aortic Sources of} Embolism

The TOAST classification system has been the gold standard tool for the diagnosis of ischemic stroke subtypes. This was revised in SSS-TOAST to account for the latest literature and to improve interexaminer reliability. Major changes in CAE risk factors include elimination of $\mathrm{LV}$ wall dyskinesia and mitral valve prolapse as sources of cardioembolism $[5,6]$.

We have shown that CMR is effective in detecting CAE sources of ischemic stroke. We have found that addition of CMR to TTE reduces incidence of cryptogenic stroke by $26 \%$. In our study, CMR detected an evident embolic source in $3(13 \%)$ patients with cryptogenic stroke, which warranted anticoagulation therapy. Our results were comparable to recent reports showing that transesophageal echocardiography (TEE) when used in addition to TTE detected an evident cardioaortic source in $8 \%$ of cryptogenic strokes necessitating anticoagulation therapy [29].

\section{Use of DE-CMR to Detect High-Risk Sources of LV \\ Thrombosis}

Recent data suggest that LV wall motion abnormalities and transmural scarring are independent risk factors for LV thrombus formation [22]. We proposed that myocardial scarring detected on DE-CMR may be used as an additional criterion for CAE risk stratification. Even though segmental wall akinesis or hypokinesis was excluded as evident sources of CAE stroke in SSS-TOAST, Weinsaft et al. [22] recently reported that risk of LV thrombus formation increased when wall motion abnormalities were accompanied by transmural scarring on DE-CMR in multiple segments and were each independent risk factors for thrombus formation. This finding is unique to DE-CMR as echocardiography is not as sensitive for the detection of myocardial scarring $[22,30]$.

We assumed that the presence of $\geq 3$ dysfunctional wall segments along with $\geq 3$ segments with scarring on DECMR sufficiently increased the risk of thrombosis to justify a CAE subtype assignment and anticoagulation. With this added criterion, addition of CMR to RDW detected a total of $9(39.1 \%)$ CAE sources in patients with cryptogenic stroke. Of these, 6 patients (26\% of the cryptogenic group) had an evident source. This rate is more than threefold greater than the data obtained with TEE, which is the standard secondary imaging technique currently used [29].

\section{Non-CAD Myocardial Scarring and Ischemic Stroke}

An interesting finding in our study is the increased incidence of non-CAD scarring in stroke patients compared to controls. Non-CAD scarring is detected on DECMR with specific features discussed elsewhere [31] and is not expected in healthy individuals. Its presence indicates some form of nonischemic myocardial injury. Although our sample was underpowered to assess a statistical significance, it raises an interesting possibility that non-CAD scarring on DE-CMR may serve as a clue to the presence of a mechanism, either cardiovascular or in the brain, which predisposes patients to a subsequent ischemic stroke. This is potentially a novel finding since this subset of patients would benefit from primary stroke prevention strategies such as prophylactic antiplatelet therapy.

\section{Study Limitations}

Although very promising, CMR has some limitations. It is more expensive than TTE and is available in fewer centers. CMR is also difficult to perform in patients with cardiac devices. Although studies continue to favor safety of CMR in patients with devices, the current consensus is that such procedure should be avoided unless medically necessary in the absence of other alternatives.

There are several limitations pertaining to our study. Our study compared the findings of CMR with TTE. Although there are no clear guidelines on the optimal imaging modality [32], it is generally believed that TEE is more sensitive than TTE in finding thrombi, especially in the LA appendage and the ascending aorta. It should be noted that all of the patients with an LA appendage thrombus in our study were classified as CAE by RDW due to atrial fibrillation. Therefore, the use of TEE in our patient population would have been superior to TTE only in detecting an aortic thrombus, which was seen in 1 patient. It is generally agreed that TTE is superior to TEE in detecting LV thrombus.

The rate of cardiogenic strokes at baseline was greater than what has been previously reported. Similarly, the rate of cryptogenic strokes was less than what is reported in previous studies. One explanation for this may be the experience of the imaging cardiologists at our center, who tend to detect subtle abnormalities that would otherwise not be noticed. Our small sample size may also contribute 
to a sampling bias. We enrolled patients who presented to only one of our stroke services. The baseline characteristics may have differed had we enrolled consecutive patients in every stroke service. Our TIA group was also substantially smaller than the stroke group. Moreover, we do not yet have long-term follow-up data to show whether subtype reclassification by CMR improved long-term outcomes. Finally, a larger sample is required in the future to evaluate clinical significance of the finding of higher non-CAD scarring incidence in the stroke population. that may substantially change the long-term management of these patients. Further studies are needed to characterize some of these findings with an adequate statistical power.

\section{Acknowledgments}

We would like to thank Jenny Richardson, Stacy Moye, Delmar Imperial-Aubin, and Don Bledose, all nurse practitioners who helped coordinating patient care.

Sources of Funding: None.

\section{Disclosure Statement}

None.

tion of CAE sources in patients with cryptogenic stroke. It provides clinicians with a unique set of information

\section{References}

1 Sacco RL, Foulkes MA, Mohr JP, Wolf PA, Hier DB, Price TR: Determinants of early recurrence of cerebral infarction. The stroke data bank. Stroke 1989;20:983-989.

- Petty GW, Brown RD Jr, Whisnant JP, Sicks JD, O’Fallon WM, Wiebers DO: Ischemic stroke subtypes: a population-based study of functional outcome, survival, and recurrence. Stroke 2000;31:1062-1068.

3 Lovett JK, Coull AJ, Rothwell PM: Early risk of recurrence by subtype of ischemic stroke in population-based incidence studies. Neurology 2004;62:569-573.

-4 Adams HP, Bendixen BH, Kappelle LJ, Biller J, Love BB, Gordon DL, Marsh EE: Classification of subtype of acute ischemic stroke. Definitions for use in a multicenter clinical trial. TOAST. Trial of Org 10172 in Acute Stroke Treatment. Stroke 1993;24:35-41.

$\checkmark 5$ Ay H, Furie KL, Singhal A, Smith WS, Sorensen AG, Koroshetz WJ: An evidencebased causative classification system for acute ischemic stroke. Ann Neurol 2005;58:688697.

6 Ay H, Benner T, Arsava EM, Furie KL, Singhal $A B$, Jensen $M B$, Ayata C, Towfighi A, Smith EE, Chong JY, Koroshetz WJ, Sorensen AG: A computerized algorithm for etiologic classification of ischemic stroke: the causative classification of stroke system. Stroke 2007; 38:2979-2984.

7 de Abreu TT, Mateus S, Correia J: Therapy implications of transthoracic echocardiography in acute ischemic stroke patients. Stroke 2005;36:1565-1566.

8 Pepi M, Evangelista A, Nihoyannopoulos P, Flachskampf FA, Athanassopoulos G, Colonna P, Habib G, Ringelstein EB, Sicari R, Zamorano JL, Sitges M, Caso P; European
Association of Echocardiography: Recommendations for echocardiography use in the diagnosis and management of cardiac sources of embolism: European Association of Echocardiography (EAE) (a registered branch of the ESC). Eur J Echocardiogr 2010; 11:461-476.

-9 Cheitlin MD, Armstrong WF, Aurigemma GP, Beller GA, Bierman FZ, Davis JL, Douglas PS, Faxon DP, Gillam LD, Kimball TR, Kussmaul WG, Pearlman AS, Philbrick JT, Rakowski H, Thys DM, Antman EM, Smith SC Jr, Alpert JS, Gregoratos G, Anderson JL, Hiratzka LF, Hunt SA, Fuster V, Jacobs AK, Gibbons RJ, Russell RO; ACC; AHA; ASE: ACC/AHA/ASE 2003 Guideline Update for the Clinical Application of Echocardiography: summary article. A report of the American College of Cardiology/American Heart Association Task Force on Practice Guidelines (ACC/AHA/ASE Committee to Update the 1997 Guidelines for the Clinical Application of Echocardiography). J Am Soc Echocardiogr 2003;16:1091-1110.

10 Pearson AC, Labovitz AJ, Tatineni S, Gomez CR: Superiority of transesophageal echocardiography in detecting cardiac source of embolism in patients with cerebral ischemia of uncertain etiology. J Am Coll Cardiol 1991; 17:66-72.

11 Sacco RL, Ellenberg JH, Mohr JP, Tatemichi TK, Hier DB, Price TR, Wolf PA: Infarcts of undetermined cause: the NINCDS Stroke Data Bank. Ann Neurol 1989;25:382-390.

12 White H, Boden-Albala B, Wang C, Elkind MSV, Rundek T, Wright CB, Sacco RL: Ischemic stroke subtype incidence among whites, blacks, and Hispanics: the Northern Manhattan Study. Circulation 2005;111:1327-1331.
13 Rustemli A, Bhatti TK, Wolff SD: Evaluating cardiac sources of embolic stroke with MRI. Echocardiography 2007;24:301-308; discussion 308.

14 Freeman WD, Aguilar MI: Prevention of cardioembolic stroke. Neurother 2011;8:488502 .

15 Harloff A, Dudler P, Frydrychowicz A, Strecker C, Stroh AL, Geibel A, Weiller C, Hetzel A, Hennig J, Markl M: Reliability of aortic MRI at 3 Tesla in patients with acute cryptogenic stroke. J Neurol Neurosurg Psychiatry 2008;79:540-546.

16 Zahuranec DB, Mueller GC, Bach DS, Stojanovska J, Brown DL, Lisabeth LD, Patel S, Hughes RM, Attili AK, Armstrong WF, Morgenstern LB: Pilot study of cardiac magnetic resonance imaging for detection of embolic source after ischemic stroke. J Stroke Cerebrovasc Dis 2012;21:794-800.

$\checkmark 17$ Hamilton-Craig C, Sestito A, Natale L, Meduri A, Santangeli P, Infusino F, Pilato F, Di Lazzaro V, Crea F, Lanza GA: Contrast transoesophageal echocardiography remains superior to contrast-enhanced cardiac magnetic resonance imaging for the diagnosis of patent foramen ovale. Eur J Echocardiogr 2011;12: 222-227.

18 Ovbiagele B, Kidwell CS, Saver JL: Epidemiological impact in the United States of a tissuebased definition of transient ischemic attack. Stroke 2003;34:919-924.

19 Ferguson GG, Eliasziw M, Barr HWK, Clagett GP, Barnes RW, Wallace MC, Taylor DW, Haynes RB, Finan JW, Hachinski VC, Barnett HJM; Collaborators ftNASCET: The North American Symptomatic Carotid Endarterectomy Trial. Stroke 1999;30:17511758.
Cardiac MRI Improves Identification of

Etiology of Acute Ischemic Stroke
Cerebrovasc Dis 2014;37:277-284 DOI: $10.1159 / 000360073$ 
20 Mulvagh SL, Rakowski H, Vannan MA, Abdelmoneim SS, Becher H, Bierig SM, Burns PN, Castello R, Coon PD, Hagen ME, Jollis JG, Kimball TR, Kitzman DW, Kronzon I, Labovitz AJ, Lang RM, Mathew J, Moir WS, Nagueh SF, Pearlman AS, Perez JE, Porter TR, Rosenbloom J, Strachan GM, Thanigaraj S, Wei K, Woo A, Yu EH, Zoghbi WA; American Society of Echocardiography: American Society of Echocardiography Consensus Statement on the Clinical Applications of Ultrasonic Contrast Agents in Echocardiography. J Am Soc Echocardiogr 2008;21:1179-1201; quiz 1281.

-21 Maceira AM, Prasad SK, Khan M, Pennell DJ: Normalized left ventricular systolic and diastolic function by steady state free precession cardiovascular magnetic resonance. J Cardiovasc Magn Reson 2006;8:417-426.

$>22$ Weinsaft JW, Kim HW, Shah DJ, Klem I, Crowley AL, Brosnan R, James OG, Patel MR, Heitner J, Parker M, Velazquez EJ, Steenbergen C, Judd RM, Kim RJ: Detection of left ventricular thrombus by delayed-enhancement cardiovascular magnetic resonance prevalence and markers in patients with systolic dysfunction. J Am Coll Cardiol 2008;52: 148-157.
23 Groves EM, Bireley W, Dill K, Carroll TJ, Carr JC: Quantitative analysis of ECG-gated highresolution contrast-enhanced MR angiography of the thoracic aorta. AJR Am J Roentgenol 2007; 188:522-528.

24 Kim RJ, Wu E, Rafael A, Chen EL, Parker MA, Simonetti O, Klocke FJ, Bonow RO, Judd RM: The use of contrast-enhanced magnetic resonance imaging to identify reversible myocardial dysfunction. N Engl J Med 2000;343: 1445-1453.

25 Micheli S, Agnelli G, Caso V, Paciaroni M: Clinical benefit of early anticoagulation in cardioembolic stroke. Cerebrovasc Dis 2008; 25:289-296.

26 Paciaroni M, Agnelli G, Micheli S, Caso V: Efficacy and safety of anticoagulant treatment in acute cardioembolic stroke: a meta-analysis of randomized controlled trials. Stroke 2007;38: 423-430.
27 Grau AJ, Weimar C, Buggle F, Heinrich A, Goertler M, Neumaier S, Glahn J, Brandt T, Hacke W, Diener HC; Collaborators obotGSDB: Risk factors, outcome, and treatment in subtypes of ischemic stroke. Stroke 2001;32:2559-2566.

28 Doufekias E, Segal AZ, Kizer JR: Cardiogenic and aortogenic brain embolism. J Am Coll Cardiol 2008;51:1049-1059.

29 Harloff A, Handke M, Reinhard M, Geibel A, Hetzel A: Therapeutic strategies after examination by transesophageal echocardiography in 503 patients with ischemic stroke. Stroke 2006;37:859-864.

30 Weinsaft JW, Kim HW, Crowley AL, Klem I, Shenoy C, Van Assche L, Brosnan R, Shah DJ, Velazquez EJ, Parker M, Judd RM, Kim RJ: LV thrombus detection by routine echocardiography: insights into performance characteristics using delayed enhancement CMR. JACC Cardiovasc Imaging 2011;4:702-712.

- 31 Senthilkumar A, Majmudar MD, Shenoy C, Kim HW, Kim RJ: Identifying the etiology: a systematic approach using delayed-enhancement cardiovascular magnetic resonance. Heart Fail Clin 2009;5:349-367, vi.

- 32 Ustrell X, Pellise A: Cardiac workup of ischemic stroke. Curr Cardiol Rev 2010;6:175183 